\title{
A genealogical map of the concept of habit
}

\author{
Xabier E. Barandiaran ${ }^{1,2 *}$ and Ezequiel A. Di Paolo Pa,4 $^{2,3}$ \\ 1 Department of Philosophy, University School of Social Work, UPV/EHU University of the Basque Country, Vitoria-Gasteiz, Spain \\ 2 Department of Logic and Philosophy of Science, IAS-Research Center for Life, Mind, and Society, UPV/EHU University of the Basque Country, \\ Donostia - San Sebastián, Spain \\ ${ }^{3}$ Ikerbasque, Basque Foundation for Science, Bilbao, Spain \\ ${ }^{4}$ Department of Informatics, Centre for Computational Neuroscience and Robotics, University of Sussex, Brighton, UK
}

\section{Edited by:}

Jose Ignacio Murillo, University of

Navarra, Spain

\section{Reviewed by:}

Nathaniel Frost Barrett, Institute for

Culture and Society, Spain

Clare Carlisle, King's College

London, UK

\section{*Correspondence:}

Xabier E. Barandiaran, Escuela

Universitaria de Trabajo Social,

UPV/EHU University of the Basque

Country, Dpto. de Filosofía, C/ Los

Apraiz, 2. 01006 - Vitoria-Gasteiz,

Araba, Spain

e-mail: xabier.academic@

barandiaran.net
The notion of information processing has dominated the study of the mind for over six decades. However, before the advent of cognitivism, one of the most prominent theoretical ideas was that of Habit. This is a concept with a rich and complex history, which is again starting to awaken interest, following recent embodied, enactive critiques of computationalist frameworks. We offer here a very brief history of the concept of habit in the form of a genealogical network-map. This serves to provide an overview of the richness of this notion and as a guide for further re-appraisal. We identify 77 thinkers and their influences, and group them into seven schools of thought. Two major trends can be distinguished. One is the associationist trend, starting with the work of Locke and Hume, developed by Hartley, Bain, and Mill to be later absorbed into behaviorism through pioneering animal psychologists (Morgan and Thorndike). This tradition conceived of habits atomistically and as automatisms (a conception later debunked by cognitivism). Another historical trend we have called organicism inherits the legacy of Aristotle and develops along German idealism, French spiritualism, pragmatism, and phenomenology. It feeds into the work of continental psychologists in the early 20th century, influencing important figures such as Merleau-Ponty, Piaget, and Gibson. But it has not yet been taken up by mainstream cognitive neuroscience and psychology. Habits, in this tradition, are seen as ecological, self-organizing structures that relate to a web of predispositions and plastic dependencies both in the agent and in the environment. In addition, they are not conceptualized in opposition to rational, volitional processes, but as transversing a continuum from reflective to embodied intentionality. These are properties that make habit a particularly attractive idea for embodied, enactive perspectives, which can now re-evaluate it in light of dynamical systems theory and complexity research.

Keywords: habit, associationism, organicism, history of psychology, history of philosophy

\section{INTRODUCTION}

For over 60 years the most basic theoretical concept in psychology, neuroscience, and cognitive science has been the processing of information and the associated notion of "mental representation." Neuroscientists search for modules and regions that process, store, retrieve or integrate information that is encoded or represented in the brain. But this hasn't always been the case. Before the advent of cognitivism in the 1950s one of the most prominent concepts for the study of mind was that of Habit. Despite constituting only very coarse evidence, the sub-plot in Figure 1 (top-left) shows trends in the use of the words "habit" and "representation" since 1850. It is noteworthy that for most of the second half of the 20th century mentions of "habit" decrease and those of "representation" increase in a sustained manner. The anti-correlation is maintained with the reversal of these tendencies at the start of the 21st century, roughly indicating that habit is again becoming a notion of interest. This is no coincidence. Current embodied dissatisfactions with the information-processing framework (Varela et al., 1991; Kelso, 1995; Van Gelder, 1998; Thompson, 2007; Chemero, 2009; Di
Paolo et al., 2010; Hutto and Myin, 2013) call for a reappraisal of this notion. The task, one quickly finds, is huge. The richness and polysemy of the notion of habit and its transformations since ancient Greece to the present day, all militate against the naive idea of producing an off-the-shelf alternative theoretical primitive for psychology and neuroscience.

In this mini-review we offer a brief genealogy of the concept of habit in the form of a network-map. We place those thinkers who have worked on this concept in a historical relation. Our objective is to outline the genealogy of the notion of habit and identify major trends and schools of thought that have had an impact on current neuroscientific conceptions of habit and those that have not but still deserve attention.

As in the case with real maps, there is potentially no end to the amount of detail that may be included. The more detailed the map, the better the chances for efficient local navigation, but often at the price of losing the big picture. We have chosen to draw only the big picture (Figure 1). For this reason, links represent a general notion of "influence" between two thinkers, without going into relevant details such as, e.g., whether the 


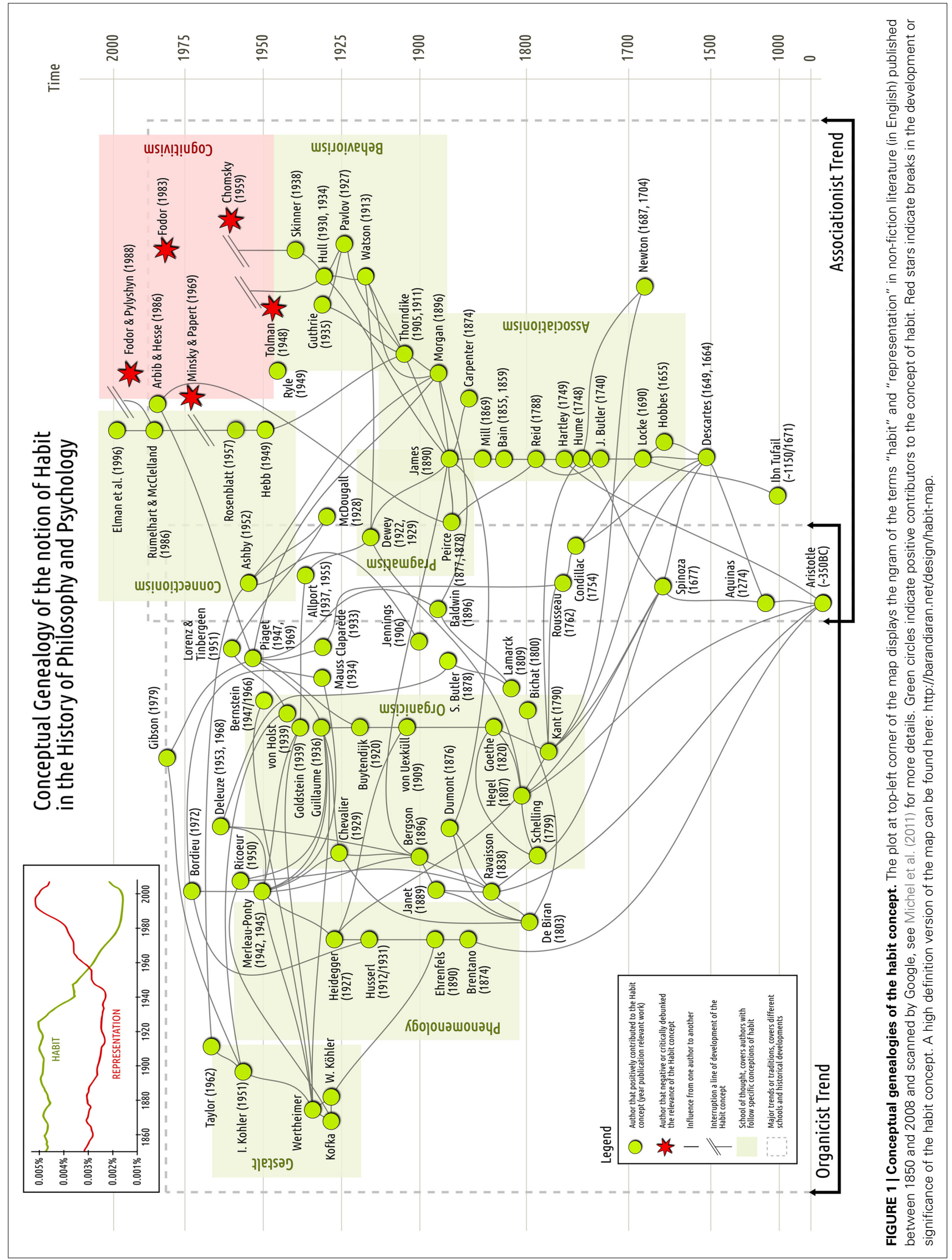


influence has been positive or critical, whether it is manifested as an explicit conceptual debt or as more subtle forms of inspiration, or indeed whether the same thinker's notion of habit has evolved significantly at different stages and under different influences.

It is likely that no two links in our map depict the exact same kind of influence. But a link describes at least an acknowledged or clearly recognized impact, which in most cases will be manifested as a direct reference to the influencing thinker in the works listed on Table 1. As a general rule transitive influences have not been drawn on the map and antagonistic links are also left out unless the critique of a previous conception of habit leads to a richer conception that integrates the view of the criticized author.

We have taken the general rule that all authors presented on the map should have discussed habits explicitly. But there are a few exceptions to this rule. For instance, Kant did not elaborate a strong positive contribution to the notion of habit-in fact, he is accountable for the ensuing divide between habit and reason in ethics-yet, his insights into the nature of teleology and self-organization strongly influenced the notion of habit, plasticity and holistic interdependence in various thinkers. Others do not make direct use of the term habit, but use parallel notions that were later (or previously) conceptualized as habits (such as von Uexküll's "functional cycles" or Pavlov's "reflexes”). The map still leaves out a considerable amount of literature on habit or habit-related research, e.g., work in economics, anthropology, psychoanalysis and research on habituation and addiction.

The timeline reaches up to the 1980 s with some additional references to later work in the cognitivist and connectionist traditions added for completeness (Elman, Rumelhart, and McClelland, Arbib, Fodor, etc.). It is worth noting that a few authors appear (almost) without connections (von Holst, Bernstein, Ryle), yet their contributions are nowadays considered important. Gestalt psychologists, who together exert a notable influence on the habit concept without addressing it directly in their work, appear without a reference in Table $\mathbf{1 .}$

The reader might still be left with a fundamental question regarding the key contribution of this map: What is the value of this genealogy for contemporary neuroscience? Whereas much work in human neuroscience appears informed by a rich philosophical, psychological and theoretical tradition (e.g., the neuroscience of perception, emotion or consciousness, cognitive or large-scale neuroscience), we believe that neuroscientific research on habit remains rooted within a narrow theoretical tradition. For instance, in an otherwise excellent review of recent work, Graybiel (2008) makes only a sparse reference to William James. Similarly, Wood and Neal (2007) only mention Thorndike and Skinner as conceptual precursors. This is understandable, as the history of habit is indeed complex and relatively unexplored. Our inherited conception appears historically distorted-only a few recent studies examine the genealogy of the concept (see Pollard, 2008; Carlisle and Sinclair, 2011; Carlisle, 2014). The map we present is an attempt to fill in this gap, providing a birds-eye view that can be used to navigate the history of the concept.

\section{TRACING THE GENEALOGIES OF HABIT}

Let us attempt a broad reading of the map. We identify two major historical trends, associationism and organicism, taking
Table 1 | List of authors and their most significant work related to habits. The year corresponds to the original publication and the title to the English translation (if available).

\begin{tabular}{|c|c|c|}
\hline Year & Author & Work \\
\hline-350 & Aristotle & $\begin{array}{l}\text { Nichomachean ethics, Metaphysics, } \\
\text { De anima, De memoria and, } \\
\text { Categories }\end{array}$ \\
\hline$\sim 1150 / 1671$ & Ibn Tufail & $\begin{array}{l}\text { Philosophus autodidactus [Risala Hayy } \\
\text { ibn Yaqzan fi asrar al-hikmat } \\
\text { al-mashriqiyya] }\end{array}$ \\
\hline 1274 & T. Aquinas & $\begin{array}{l}\text { Summa theologica (Treatise on habit } \\
\text { Q049-54) }\end{array}$ \\
\hline 1649,1664 & R. Descartes & $\begin{array}{l}\text { The passions of the soul and Treatise } \\
\text { of man }\end{array}$ \\
\hline 1655 & T. Hobbes & De corpore \\
\hline 1677 & B. Spinoza & Ethics \\
\hline 1687,1704 & I. Newton & $\begin{array}{l}\text { Philosophiae naturalis Principia } \\
\text { mathematica and Opticks }\end{array}$ \\
\hline 1690 & J. Locke & $\begin{array}{l}\text { An essay concerning human } \\
\text { understanding }\end{array}$ \\
\hline 1739,1748 & D. Hume & $\begin{array}{l}\text { A treatise of human nature and } \\
\text { Enquiry concerning human } \\
\text { understanding }\end{array}$ \\
\hline 1740 & J. Butler & $\begin{array}{l}\text { The analogy of religion, natural and } \\
\text { revealed, to the constitution and } \\
\text { course of nature }\end{array}$ \\
\hline 1749 & D. Hartley & $\begin{array}{l}\text { Observations on man, his frame, his } \\
\text { duty, and his expectations }\end{array}$ \\
\hline 1754 & E. B. de Condillac & Treatise on the sensations \\
\hline 1762 & J-J Rousseau & Émile or On education \\
\hline 1788 & T. Reid & $\begin{array}{l}\text { Essays on the active powers of the } \\
\text { human mind }\end{array}$ \\
\hline 1790 & E. Kant & Critique of judgment \\
\hline 1799 & F. W. J. Schelling & $\begin{array}{l}\text { First outline for a system of a } \\
\text { philosophy of nature }\end{array}$ \\
\hline 1800 & X. Bichat & $\begin{array}{l}\text { Recherches physiologiques sur la vie } \\
\text { et la mort }\end{array}$ \\
\hline 1803 & M. de Biran & $\begin{array}{l}\text { Influence de l'habitude sur la faculté } \\
\text { de penser }\end{array}$ \\
\hline 1809 & J. B. P. Lamarck & Zoological philosophy \\
\hline 1820 & J. W. Goethe & $\begin{array}{l}\text { Outline for a general introduction } \\
\text { comparative anatomy, Commencing } \\
\text { osteology }\end{array}$ \\
\hline 1830 & G. W. F. Hegel & $\begin{array}{l}\text { The philosophy of mind (Part } 3 \text { of the } \\
\text { Encyclopaedia of the philosophical } \\
\text { sciences) }\end{array}$ \\
\hline 1838 & F. Ravaisson & Of habit \\
\hline 1855,1859 & A. Bain & $\begin{array}{l}\text { Senses and the intellect, The } \\
\text { emotions and the will }\end{array}$ \\
\hline 1869 & J. Mill & $\begin{array}{l}\text { Analysis of the phenomena of the } \\
\text { human mind }\end{array}$ \\
\hline 1874 & W. B. Carpenter & Principles of mental physiology \\
\hline 1874 & F. C. Brentano & $\begin{array}{l}\text { Psychology from an empirical } \\
\text { standpoint }\end{array}$ \\
\hline 1876 & L. Dumont & $\begin{array}{l}\text { De I'habitude (Rev. Phil de la France et } \\
\text { de l'Etranger) }\end{array}$ \\
\hline
\end{tabular}

(Continued) 
Table 1 | Continued

\begin{tabular}{|c|c|c|}
\hline Year & Author & Work \\
\hline 1877, 1878 & C. S. Peirce & $\begin{array}{l}\text { The fixation of belief, How to make } \\
\text { ideas clear (see also Collected Papers) }\end{array}$ \\
\hline 1878 & S. Butler & Life and habit \\
\hline 1889 & P. Janet & L'Automatisme psychologique \\
\hline 1890 & C. von Ehrenfels & Über Gestaltqualitäten \\
\hline 1890 & W. James & Principles of psychology (Ch. 4 Habit) \\
\hline 1896 & J. M. Baldwin & $\begin{array}{l}\text { Mental development in the child and } \\
\text { the race: Methods and processes }\end{array}$ \\
\hline 1896 & C. L. Morgan & Habit and instinct \\
\hline 1896 & H. Bergson & Matter and memory \\
\hline 1905, 1911 & E. Thorndike & $\begin{array}{l}\text { Elements of psychology, Animal } \\
\text { intelligence: Experimental studies }\end{array}$ \\
\hline 1906 & H. S. Jennings & Behavior of the lower organisms \\
\hline 1909 & J. von Uexküll & Umwelt und Innenwelt der Tiere \\
\hline 1912 & E. Husserl & $\begin{array}{l}\text { Ideas: General introduction to pure } \\
\text { phenomenology (Part II) }\end{array}$ \\
\hline 1913 & J. B. Watson & Psychology as the behaviorist views it \\
\hline 1920 & F. J. J. Buytendijk & Psychologie der dieren \\
\hline 1922,1929 & J. Dewey & $\begin{array}{l}\text { Human nature and conduct, } \\
\text { Experience and Nature }\end{array}$ \\
\hline 1927 & M. Heidegger & Being and time \\
\hline 1927 & I. P. Pavlov & Conditioned reflexes \\
\hline 1928 & W. McDougall & $\begin{array}{l}\text { Body and mind; A history and a } \\
\text { defence of animism }\end{array}$ \\
\hline 1929 & J. Chevallier & $\begin{array}{l}\text { L'habitude: essai de métaphysique } \\
\text { scientifique }\end{array}$ \\
\hline 1930, 1934 & C. L. Hull & $\begin{array}{l}\text { Knowledge and purpose as habit } \\
\text { mechanisms, The concept of the } \\
\text { habit-family hierarchy and maze } \\
\text { learning }\end{array}$ \\
\hline 1933 & E. Claparède & $\begin{array}{l}\text { La Genèse de l'hypothèse: étude } \\
\text { expérimentale }\end{array}$ \\
\hline 1934 & M. Mauss & Techniques of the body \\
\hline 1934 & K. Goldstein & The organism \\
\hline 1935 & E. von Holst & $\begin{array}{l}\text { Relative coordination as a } \\
\text { phenomenon and as a method of } \\
\text { analysis of central nervous system } \\
\text { function }\end{array}$ \\
\hline 1935 & E. R. Guthrie & The psychology of learning \\
\hline 1936 & P. Guillaume & La formation des habitudes \\
\hline 1937, 1955 & G. Allport & $\begin{array}{l}\text { The functional autonomy of motives, } \\
\text { Becoming }\end{array}$ \\
\hline 1938 & B. F. Skinner & $\begin{array}{l}\text { The behavior of organisms: An } \\
\text { experimental analysis }\end{array}$ \\
\hline 1942,1945 & M. Merleau-Ponty & $\begin{array}{l}\text { The structure of behavior, } \\
\text { Phenomenology of perception }\end{array}$ \\
\hline 1947,1969 & J. Piaget & $\begin{array}{l}\text { The psychology of intelligence, } \\
\text { Biology and knowledge }\end{array}$ \\
\hline $1947 / 1967$ & N. Bernstein & $\begin{array}{l}\text { The co-ordination and regulation of } \\
\text { movements see also Dexterity and its } \\
\text { development (1996) }\end{array}$ \\
\hline 1948 & E. C. Tolman & Cognitive maps in rats and men \\
\hline 1949 & G. Ryle & The concept of mind \\
\hline 1949 & D. Hebb & Organization of behavior \\
\hline
\end{tabular}

(Continued)
Table 1 | Continued

\begin{tabular}{|c|c|c|}
\hline Year & Author & Work \\
\hline 1950 & P. Ricoeur & $\begin{array}{l}\text { Freedom and nature: The voluntary } \\
\text { and the involuntary }\end{array}$ \\
\hline 1951 & $\begin{array}{l}\text { K. Lorenz \& N. } \\
\text { Timbergeen }\end{array}$ & The study of instinct \\
\hline 1951 & I. Kohler & $\begin{array}{l}\text { The formation and transformation of } \\
\text { the perceptual world (1964) }\end{array}$ \\
\hline 1952 & W. R. Ashby & Design for a brain \\
\hline 1953, 1968 & G. Deleuze & $\begin{array}{l}\text { Difference and repetition, Empiricism } \\
\text { and subjectivity }\end{array}$ \\
\hline 1957 & F. Rosenblatt & $\begin{array}{l}\text { The perceptron: A probabilistic model } \\
\text { for information storage and } \\
\text { organization in the brain }\end{array}$ \\
\hline 1959 & N. Chomsky & $\begin{array}{l}\text { A review of B. F. Skinner's Verbal } \\
\text { behavior }\end{array}$ \\
\hline 1962 & J. G. Taylor & The behavioral basis of perception \\
\hline 1969 & $\begin{array}{l}\text { M. L. Minsky \& S. } \\
\text { Papert }\end{array}$ & $\begin{array}{l}\text { Perceptrons: An introduction to } \\
\text { computational geometry }\end{array}$ \\
\hline 1972 & P. Bourdieu & Outline of a theory of practice (1977) \\
\hline 1979 & J. J. Gibson & $\begin{array}{l}\text { The ecological approach to visual } \\
\text { perception }\end{array}$ \\
\hline 1983 & J. Fodor & $\begin{array}{l}\text { The modularity of mind: an essay on } \\
\text { faculty psychology }\end{array}$ \\
\hline 1986 & $\begin{array}{l}\text { M. A. Arbib and M. } \\
\text { B. Hesse }\end{array}$ & The construction of reality \\
\hline 1986 & $\begin{array}{l}\text { D. E. Rumelhart, J. } \\
\text { L. McClelland and } \\
\text { PDP Group }\end{array}$ & $\begin{array}{l}\text { Parallel distributed processing, Vol. 1: } \\
\text { Foundations }\end{array}$ \\
\hline 1988 & $\begin{array}{l}\text { J. Fodor and Z. W. } \\
\text { Pylyshyn }\end{array}$ & $\begin{array}{l}\text { Connectionism and cognitive } \\
\text { architecture: A critical analysis }\end{array}$ \\
\hline 1996 & J. L. Elman et al. & $\begin{array}{l}\text { Rethinking innateness: A } \\
\text { connectionist perspective on } \\
\text { development }\end{array}$ \\
\hline
\end{tabular}

their names from the most salient school of thought in each trend. But we shall first start from the Greek and Aristotelian polysemic conception of habit.

The Latin term habitus, from which the English habit comes, can be traced back to two Greek words: ethos (' $(\tilde{\varepsilon} \xi ı)$. The etymology of ethos, from which the English term ethics derives, is particularly revealing because it contains a profound duality. It means both "an accustomed place" in which human and animals live or in-habit (a "habitat") and "a disposition or character" denoting the personality that develops along a person's lifetime. According to Aristotle, the term hexis (having or being in possession of something) is a relational and active category: "a kind of activity of the haver and of what he hassomething like an action or movement" [Met. 5.1022b] $]^{1}$, it is also a normative dispositional category "'Having' or 'habit' means a disposition according to which that which is disposed is either well or ill disposed" [Met. 5.1022b]. The ethical implications of this conception of habit extend to a self-modifying practice,

\footnotetext{
${ }^{1}$ References given between square brackets correspond to works used in constructing the map. They are listed in Table 1.
} 
exercised so as to attain a virtuous character wherein spontaneity, joy, and norms converge.

We can interpret the Aristotelian conception of habit as an arrangement of behavioral mediations between subject and object (or between a subject and herself-in the future or past) that is well or ill-disposed in relation to essence or form and the "immediate substrate in which it is naturally produced." Habit arises from custom or repetition in a manner that constitutes a sort of second nature for the subject. In this sense, Aristotle can be said to be one of the early precursors of the organicist trend in the conception of habit. But he is also credited for inspiring the central claim of associationism (Buckingham and Finger, 1997).

\section{THE ASSOCIATIONIST TREND}

Associationism can be summarized as the view that mental phenomena are formed by combination or association of simple elements. This association follows the principle that the occurrence of event $B$ given event $A$ will be favored if $B$ has repeatedly followed A in the past (often, the strength of A or B, their similarity, space-time contiguity, etc. are taken as strengthening this association). A and B are generally considered as mental states or ideas arising from sensations (often interpreted in terms of nervous activation).

The work of Ibn Tufail (12th century), translated into Latin as Philosophus Autodidactus [1671], tells the story of a child that reconstructs a full philosophical and theological system without the help of a social or cultural environment. It influenced the first associationists, particularly John Locke whose notion of tabula rasa was almost directly taken from Ibn Tufail (Russell, 1994). Locke's empiricist principle- that sense data had to fill in a blank slate-provided the basis of what was to come although he didn't provide a detailed account of associationism².

It was David Hume [1748] who proposed the notion of "habit," "custom," or "association" as the fundamental mechanism for the development of psychological and epistemological complexes. Atomized ideas are the direct result of sensations, while the law of habit becomes the general principle of mental organization by linking these ideas. Newton's influence on this conception of habit is apparent. Although the principles established by Hume are not fundamentally modified by Hartley's work, the latter was capable of extending them to many psychological phenomena (from memory to language, psychological development and emotions). Perhaps one of the most salient contributions was Hartley's account of habits as arising from "corporeal matter," completing Hume's philosophical approach with an influential neuro-physiological theory of associations based on the operations of the brain and the spinal cord, in accordance with the "doctrine of vibrations" previously suggested by Newton (Glassman and Buckingham, 2007). Further contributors to the associationist school (Bain, Mill, Carpenter, etc.) conserved most of the principles and theoretical assumptions of Hume and Hartley until a scientific formulation of some of these principles by behaviorist precursors came from the scientific study of animal behavior (Morgan, Thorndike and Pavlov).

\footnotetext{
${ }^{2}$ Except for chapter 33 in his Essay introduced only in the 4th edition and dealing mostly with the origin of confusion and mistaken ideas.
}

The subsequent development of the notion of habit was subordinated to the available methods of measurement and intervention, which aimed at the "prediction and control of behavior" [Watson, 1913: 158]. The contribution of behaviorism to this trend can be summarized in two main aspects that result from the epistemological constraints of logical positivism (Smith, 1986) on the notion of habit: (a) the progressive externalization of the units of association in terms of stimulus and response (removing any reference to intermediate neurological or psychological processes) and (b) the mathematical treatment of the relationship between external operators and observables (stimulus, response, reinforcers) in terms of conditional probabilities. Skinner even rejected learning theories (Skinner, 1950) and purified the available terminology dropping the notion of habit altogether in favor of "rate of conditioned response."

At this point, together with the advent of computational and information theory, the ground was prepared for the now much impoverished notion of habit to disappear altogether from the set of theoretical primitives in psychology and neuroscience. Through experimental [Tolman, 1948] and theoretical [Chomsky, 1959; Fodor, 1983] arguments against behaviorism, habit was soon replaced by "mental representation" and the notion of "association" was substituted by that of "computation." Some of the associationist (and also organicist) principles were revived in neuroscience [Hebb, 1949] and, particularly, in connectionism [Rosenblatt, 1957; Rumerhart and McClelland, 1987] only to be fiercely attacked again by cognitivists [Minsky and Papert, 1969; Fodor and Pylyshyn, 1988] $]^{3}$. The result of this development is the current convergence of machine learning and reinforcement learning with neuroscience (see Sutton and Barto, 1998; Daw et al., 2005; Dezfouli et al., 2012) where habits have been subsumed under networks of conditional probabilities of expected rewards associated with a set of available actions under specific conditions, or simply reduced to stimulus-triggered responses reinforced only by repetition (Dickinson, 1985). Associationist principles still exert an influence in neuroscience under the form of Hebbian learning and activity-dependent plasticity (Abbott and Nelson, 2000).

\section{THE ORGANICIST TREND}

Somewhat parallel to the development of the associationist trend we encounter an organicist tradition (left of Figure 1). Habits in this tradition are examined along what we would call today more ecological, self-organizing lines. Habits are both cause and effect of their own enactment and therefore constitute their own principle of individuation (Toscano, 2006), as opposed to being the passive result of the recurrence of an otherwise pre-established set of entities (ideas, stimulus, rewards, etc.). For organicism, habits are also related to a plastic equilibrium that involves the totality of the organism, including other habits, the body and the habitat they co-determine.

Spinoza's notion of conatus, as the striving for perseverance that defines the essence of organisms, prefigured the internalist and naturalistic conception of individuality and teleology

\footnotetext{
${ }^{3}$ For a detailed account of these developments and intellectual battles, see Margaret Boden's monumental history of cognitive science (Boden, 2006).
} 
that characterizes organicism. Kant [1790] provided a regulative notion of teleology in terms of the intertwinement of means and ends in the self-organized nature of organic life, thereby insinuating a way out of the tight mechanistic framework established by Descartes and Newton. Hegel [1830], in deep dialog with the Aristotelian tradition, emphasized the plasticity of habit as the mediating term in the resolution of the mind's contradictory tendencies toward world-independence and self-determination on the one hand, and over-stimulation and world-determination, on the other. By becoming second nature, habit prevents the mind from falling into either extreme that would lead to insanity. Goethe (though not directly addressing the notion of habit) deeply influenced subsequent conceptions of organic life by coining the term "morphology" and proposing the law of compensation to refer to the plastic change of natural forms in accordance with inner forces that respect the balance of the totality [1820]. Ravaisson's De l'habitude [1838] constitutes a cornerstone within this trend. Ravaisson puts habits at the center of metaphysics, extending from vegetative life to deliberative thought, defining habits as dynamical processes that transverse a continuum between reflective/self-aware and pre-reflective/embodied forms of intentionality (Sinclair, 2011).

Further development of the habit notion within the organicist school made it possible to expand on the dialectics between the inner tendencies of organic individuality and its co-development with the environment. von Uexküll [1909] used the term Umwelt to designate the habitat of the organism, that is, the carving of a world (from an undifferentiated environment) through functional sensorimotor cycles. His work was part of an organicist revival in Central Europe during the first half of the 20th century (Grene, 1965; Harrington, 1996), with notable exponents like the phenomenologically-informed psychologist/ethologist F. J. J. Buytendijk and neurologist Kurt Goldstein, whose studies of abstract vs. concrete behaviors in patients with brain lesions led him to holistic notions of the organism as seeking the equilibrium of preferred behaviors.

Somewhat intertwined within the organicist school, phenomenology and Gestalt psychology enriched this tradition in various ways. Husserl, for instance, acknowledged that habit is "intimately involved in the constitution of meaningfulness" at all levels, from perception to society (Moran, 2011). Merleau-Ponty [1945] drew inspiration from Paul Guillaume's Gestalt approach and Goldstein's experiments to develop a notion of habits as incorporated styles of being-in-the-world, thus revealing their inherent corporeal intentionality in contrast to notions of habits as blind automatisms. Gestalt psychology provided a systematic and experimental basis for holistic phenomena in perception, displacing atomistic metaphors in psychology in favor of fields and systems theory. Of particular significance are the experiments with vision distorting goggles by Ivo Kohler [1962] who emphasized the importance of action for perception, combining an active notion of habit with Gestalt principles.

Overall, the exponents of the organicist tradition in the 20th century pronounced themselves explicitly against atomistic tendencies, such as the localization of brain function and theories of reflex conditioning. The trend also influenced pragmatist thinkers such as James [1890], and particularly Dewey [1922], who also saw habits as communicating wholes affecting each other and as the substrate of self-transforming human nature. He resisted the reductionist implications of the reflex-arc concept by highlighting the active role of the organism in the selection of stimuli.

Organicism, whose ramifications appear less unified and cumulative than the associationist line, has influenced a variety of positions ranging from the integrative work of Piaget (his treatment of habit marks the starting point for a dynamic conception of cognitive development) to ecological psychology [Gibson, 1979], and the sociological conception of habitus as structured and structuring practices [Mauss, 1934; Bourdieu, 1972].

Current sensitivity to the organicist trend is manifest in largescale neuroscience (Edelman and Tononi, 2001; Freeman, 2001; Llinas, 2001), constructivist developmental neuroscience (Quartz and Sejnowski, 1997; Johnson, 2001), embodied-enactive cognitive science (Varela et al., 1991; Thompson, 2007; Di Paolo et al., 2010), robotics (Di Paolo, 2003; Egbert and Barandiaran, under review), sensorimotor approaches to cognition (O'Regan and Noë, 2001; Noë, 2004) and cognitive neuroscience (Engel et al., 2013). In most cases the concept of habit forged by the organicist tradition has been modified to avoid the critiques against behaviorism, and its legacy appears to be masked under related notions such as skill, sensorimotor organization, neuroplasticity, etc.

\section{CONCLUSIONS}

We have provided a map and a very broad survey of the various ways in which the concept of habit has evolved from ancient Greece to the late 1980s, identifying two major traditions. The associationist trend conceives of habits atomistically as units that result from the association of ideas or between stimulus and response. The organicist trend, in contrast, sees habits as dynamically configured stable patterns, strengthened and individualized by their enactment. Associationism provides a statistical or combinatorial relationship between the components of a habit (based on time lapses between events, their similarity, etc.). Organicism, in contrast, proposes a more holistic view, wherein embodied relational constraints and plastic interdependencies determine the formation and maintenance of habits. Finally, the associationist trend keeps habit within the realm of reactive sub-personal automatisms (in opposition to the intentional, rational, and personal levels of cognitive processing). For organicism, in contrast, habits transition between nature and will, forming an integral part of individual embodied intentionality; they are the systemic conditions of the possibility of experience-their significance becomes clearly manifested when habits are disturbed yet they remain continuously present, configuring the identity and world of the cognitive subject.

Unlike many notions in organicism, associationist ideas were ready-made for translation into scientific hypotheses during the 20 th century, even if it was ironically the subsequent development of such formalisms that fueled the cognitivist rejection of the notion of habit. While neuroscience has been partially influenced by this rejection, related ideas have survived, particularly in theories of neuroplasticity and Hebbian learning. These habitlike notions are generally associationist in character, but they have also given rise to theories of neural assemblies and neural 
self-organization (Varela, 1995; Freeman, 2001), which are more organicist-friendly. Similarly, in other areas of cognitive science, dynamical systems formalisms, modeling and experimental techniques now provide the necessary tools for investigating more organicist conceptions of habit.

\section{ACKNOWLEDGMENTS}

This work is funded by the eSMCs: Extending Sensorimotor Contingencies to Cognition project, FP7-ICT-2009-6 no: 270212. XEB hold a Postdoc with the FECYT foundation (funded by Programa Nacional de Movilidad de Recursos Humanos del MEC-MICINN, Plan I-D+I 2008-2011, Spain) during the development of this work and acknowledges IAS-Research group funding IT590-13 from the Basque Government.

\section{REFERENCES 4}

Abbott, L. F., and Nelson, S. B. (2000). Synaptic plasticity: taming the beast. Nat. Neurosci. 3, 1178-1183. doi: 10.1038/81453

Boden, M. (2006). Mind as Machine: A History of Cognitive Science, Vol. 2. Oxford: Oxford University Press.

Buckingham, H. W., and Finger, S. (1997). David Hartley's psychobiological associationism and the legacy of Aristotle. J. Hist. Neurosci. 6, 21-37. doi: 10.1080/09647049709525683

Carlisle, C. (2014). On Habit. London: Routledge.

Carlisle, C., and Sinclair, M. (eds.). (2011). Habit. J. Br. Soc. Phenomenol. 42:1.

Chemero, A. (2009). Radical Embodied Cognitive Science. Cambridge, MA: MIT Press.

Daw, N. D., Niv, Y., and Dayan, P. (2005). Uncertainty-based competition between prefrontal and dorsolateral striatal systems for behavioral control. Nat. Neurosci. 8, 1704-1711. doi: 10.1038/nn1560

Dezfouli, A., Balleine, B. W., Dezfouli, A., and Balleine, B. W. (2012). Habits, action sequences and reinforcement learning. Eur. J. Neurosci. 35, 1036-1051. doi: 10.1111/j.1460-9568.2012.08050.x

Dickinson, A. (1985). Actions and habits: the development of behavioural autonomy. Philos. Trans. R. Soc. Lond. Ser. B Biol. Sci. 308, 67-78. doi: 10.1098/rstb.1985.0010

Di Paolo, E. A. (2003). "Organismically-inspired robotics: homeostatic adaptation and teleology beyond the closed sensorimotor loop," in Dynamical Systems Approaches to Embodiment and Sociality eds K. Murase and Asakura (Adelaide: Advanced Knowledge International), 19-42.

Di Paolo, E. A., Rohde, M., and De Jaegher, H. (2010). "Horizons for the enactive mind: values, social interaction, and play," in Enaction. Toward a New Paradigm for Cognitive Science, eds J. Stewart, O. Gapenne and E. A. Di Paolo (Cambridge, MA: MIT Press), 33-87.

Edelman, G., and Tononi, G. (2001). A Universe of Consciousness How Matter Becomes Imagination. New York, NY: Basic Books.

Engel, A. K., Maye, A., Kurthen, M., and König, P. (2013). Where's the action? The pragmatic turn in cognitive science. Trends Cogn. Sci. 17, 202-209. doi: 10.1016/j.tics.2013.03.006

Freeman, W. J. (2001). How Brains Make Up their Minds. 1st Edn. New York, NY: Columbia University Press.

Glassman, R. B., and Buckingham, H. W. (2007). "David Hartley's neural vibrations and psychological associations," in Brain, Mind and Medicine: Essays in Eighteenth-Century Neuroscience, eds H. Whitaker, C. U. M. Smith, and S. Finger (New York, NY: Springer), 177-190.

Graybiel, A. M. (2008). Habits, rituals, and the evaluative brain. Ann. Rev. Neurosci. 31, 359-387. doi: 10.1146/annurev.neuro.29.051605.112851

Grene, M. (1965). Approaches to a Philosophical Biology, New York, NY: Basic Books.
Harrington, A. (1996). Reenchanted Science: Holism in German Culture from Wilhem II to Hitler. Princeton, NJ: Princeton University Press.

Hutto, D. D., and Myin, E. (2013). Radicalizing Enactivism: Basic Minds without Content. Cambridge, MA: MIT Press.

Johnson, M. H. (2001). Functional brain development in humans. Nat. Rev. Neurosci. 2, 475-483. doi: 10.1038/35081509

Kelso, J. A. S. (1995). Dynamic Patterns: The Self-Organization of Brain and Behavior. Cambridge, MA: MIT Press.

Llinas, R. R. (2001). I of the Vortex: From Neurons to Self. Cambridge, MA: MIT Press.

Michel, J.-B., Shen, Y. K., Aiden, A. P., Veres, A., Gray, M. K., Pickett, J. P., et al. (2011). Quantitative analysis of culture using millions of digitized books. Science 331, 176-182. doi: 10.1126/science.1199644

Moran, D. (2011). Edmund Husserl's phenomenology of habituality and habitus. J. Br. Soc. Phenomenol. 42, 53-77.

Noë, A. (2004). Action in Perception. Cambridge, MA: MIT Press.

O'Regan, J. K., and Noë, A. (2001). A sensorimotor account of vision and visual consciousness. Behav. Brain Sci. 24, 939-1031. doi: 10.1017/S0140525X01 000115

Pollard, B. (2008). Habits in Action. A Corrective to the Neglect of Habits in Contemporary Philosophy of Action, Saarbrücken: VDM Verlag Dr. Mueller.

Quartz, S. R., and Sejnowski, T. J. (1997). The neural basis of cognitive development: a constructivist manifesto. Behav. Brain Sci. 20, 537-556. doi: 10.1017/S0140525X97001581

Russell, G. A. (1994). "The impact of the philosophus autodidactus: Pocockes, John Locke, and the society of friends," in The 'Arabick' Interest of the Natural Philosophers in Seventeenth-Century England, ed G. A. Russell (Leiden: E. J. Brill), 224-265.

Sinclair, M. (2011). Ravaisson and the force of habit. J. Hist. Philos. 49, 65-85.

Skinner, B. F. (1950). Are theories of learning necessary? Psychol. Rev. 57, 193-216. doi: $10.1037 / \mathrm{h} 0054367$

Smith, L. D. (1986). Behaviorism and Logical Positivism: A Reassessment of the Alliance. Stanford, CA: Stanford University Press.

Sutton, R. S., and Barto, A. G. (1998). Reinforcement Learning. Cambridge, MA: MIT Press.

Thompson, E. (2007). Mind in Life: Biology, Phenomenology, and the Sciences of Mind. Cambridge, MA: Harvard University Press.

Toscano, A. (2006). The Theatre of Production: Philosophy and Individuation between Kant and Deleuze. Basingstoke: Palgrave Macmillan. doi: $10.1057 / 9780230514195$

Van Gelder, T. (1998). The dynamical hypothesis in cognitive science. Behav. Brain Sci. 21, 615-628. doi: 10.1017/S0140525X98001733

Varela, F. J. (1995). Resonant cell assemblies: a new approach to cognitive functions and neuronal synchrony. Biol. Res. 28, 81-95.

Varela, F. J., Thompson, E., and Rosch, E. (1991). The Embodied Mind: Cognitive Science and Human Experience. Cambridge, MA: MIT Press.

Wood, W., and Neal, D. T. (2007). A new look at habits and the habit-goal interface. Psychol. Rev. 114, 843-863. doi: 10.1037/0033-295X.114.4.843

Conflict of Interest Statement: The authors declare that the research was conducted in the absence of any commercial or financial relationships that could be construed as a potential conflict of interest.

Received: 30 March 2014; accepted: 27 June 2014; published online: 21 July 2014. Citation: Barandiaran XE and Di Paolo EA (2014) A genealogical map of the concept of habit. Front. Hum. Neurosci. 8:522. doi: 10.3389/fnhum.2014.00522

This article was submitted to the journal Frontiers in Human Neuroscience. Copyright (c) 2014 Barandiaran and Di Paolo. This is an open-access article distributed under the terms of the Creative Commons Attribution License (CC BY). The use, distribution or reproduction in other forums is permitted, provided the original author(s) or licensor are credited and that the original publication in this journal is cited, in accordance with accepted academic practice. No use, distribution or reproduction is permitted which does not comply with these terms.

\footnotetext{
${ }^{4}$ References to the work of authors appearing in the map are marked with square brackets in the text (e.g. Ravaisson [1838]) and are listed in Table 1.
} 